\title{
Non-functional Pituitary Carcinoma
}

\author{
Haiyong He $M D^{1}$ (iD), Ying Guo $M D^{2}$ iD, Manting Li $M D^{3}$ iD, Lun Luo $M D^{4}$ iD, \\ Robin Bhattarai $M D^{5}$ iD, Wensheng Li $M D^{6}$ iD \\ 1,2,3,4,6 Department of Neurosurgery, Third Affiliated Hospital of Sun Yat-sen University, Guangzhou, \\ Guangdong, PR China \\ ${ }^{5}$ B \& C Medical College Teaching Hospital \& Research Centre Pvt. Ltd., Birtamode, Nepal
}

Date of submission: 22 ${ }^{\text {nd }}$ August 2021

Date of acceptance: $14^{\text {th }}$ November 2021

Date of publication: $1^{\text {st }}$ December 2021

\begin{abstract}
We present as case to review and present the clinical features, diagnosis and treatment of non-functional pituitary carcinoma (NFPC).

We operated on a case of NFPC. After surgery, gamma knife therapy, temozolomide chemotherapy and whole craniospinal irradiation, the patient still had poor tumor control and died 7 months after operation.

NFPC is very rare. It needs to be diagnosed with a combination of clinical suspicion, imaging and dynamic monitoring. It is necessary to find more effective methods to control the progress of tumor while routine treatment fails.
\end{abstract}

Key words: Craniospinal irradiation, Endoscopic transsphenoidal approach, Non-functional pituitary carcinoma, Temozolomide

\section{Introduction}

$\mathrm{P}$ ituitary adenocarcinoma is very rare, accounting for about $0.1 \%-0.2 \%$ of pituitary tumors. ${ }^{1}$ Pituitary adenocarcinoma mainly occurs in adults. Their clinical manifestations vary with the characteristics of endocrinology and oncology. $75 \%$ of pituitary adenocarcinomas are hormone secreting tumors; most of them secrete PRL and ACTH, accompanied by corresponding endocrinological pathological changes. About $10-30 \%$ of pituitary adenocarcinoma is nonfunctional, and its clinical treatment is more difficult. ${ }^{2}$ This paper reports a case of non-functional pituitary carcinoma

\section{Access this article online}

Website: https://www.nepjol.info/index.php/NJN

DOI: https://doi.org/10.3126/njn.v18i4.39301

HOW TO CITE

He H, Guo Y, Li M, Luo M, Bhattarai R, Li W. Non-functional Pituitary Carcinoma. NJNS. 2021;18(4):49-53.

\section{Address for correspondence:}

Dr Wensheng Li, MD,

Department of Neurosurgery,

Third Affiliated Hospital of Sun Yat-sen University,

No. 600 Tianhe Road, Tianhe district,

Guangzhou, Guangdong Province, 510630, PR China

E-mail: sums3neuro@126.com

Phone: +86-013902260029

Copyright (C) 2021 Nepalese Society of Neurosurgeons (NESON)

ISSN: 1813-1948 (Print), 1813-1956 (Online)

This work is licensed under a Creative Commons Attribution-Non Commercial 4.0 International License.
(NFPC) treated in neurosurgery department of the Third Affiliated Hospital of Sun Yat-sen University in 2018, and discusses the diagnosis and treatment strategy of NFPC combined with related literature review.

\section{Case report}

A 35-year-old woman presented to the hospital with the chief complaint of visual disturbance and headache for 2 months on July 31, 2018, accompanied by irregular menstruation and thirst, with a daily urine volume of about $4000 \mathrm{ml}$. Physical examination revealed bilateral round and equal size pupils with presence of direct and indirect pupillary reactions to light. There was no obvious abnormality in other nervous system examinations. Hormone levels (on admission): thyroid function: T4: $43.02 \mathrm{nmol} / \mathrm{L}(62.68-150.84 \mathrm{nmol} / \mathrm{L}), \mathrm{FT} 4: 7.80 \mathrm{pmol} /$ L (9.01-19.05 pmol / L), GH: normal; IGF-1: $139 \mathrm{ng} / \mathrm{ml}$ (116-359 ng / ml), PRL 1784.81 mIU / L (108.8-557.1 mIU ( L), and the levels of other sex hormones were normal. 8am-4pm-0am Cor < $13.79 \mathrm{nmol} / \mathrm{L}$ (normal range 8am: 145.4-619.4 nmol/L; 4pm\&0am: 94.9-462.4 nmol/L), the other hormone levels were not significantly abnormal. Hydrocortisone (20mg, bid; Shanghai Pharma, China) replacement therapy was given before operation. Head CT scan and pituitary MRI enhanced scan showed a sellar tumour invading through the sellar floor, had protruded into the sphenoid sinus. It also invaded the cavernous sinus and grew into suprasellar cistern (Hardy 4A, Knosp 3 grade). (Figure 1 A-D)

The tumor was partially removed by endoscopic transsphenoidal approach. Its texture was hard, and the boundary with normal tissue was not clear. The tumor in 


\section{He et al}

the sphenoid sinus region was removed, and the tumor in the sella and cavernous sinus were partially resected. (Figure.1 E-H, Figure. 2)

Hydrocortisone (20mg, bid) and Levothyroxine Sodium Tablets (euthyrox, 50ug, qd; Merck KGaA, Darmstadt, Germany) were used for hormone replacement therapy after the operation. One month after the operation, the thyroid function was FT4 $8.20 \mathrm{pmol} / \mathrm{L}$ (9.01-19.05 $\mathrm{pmol} / \mathrm{L})$, TSH $0.6283 \mathrm{uIU} / \mathrm{ml}$ and Cor (8am) $89.32 \mathrm{nmol}$ / L. The histopathologic examination suggested that the mass was an invasive non-functional pituitary adenoma. The immunohistochemical staining showed that the cells were positive for Vimt and p53; focal positive for CD38 and CD138; scattered or partly positive for CD3, CD45R0, CD20, CD79a, CD56, S100, Bcl-2, CD99 and EmA; the Ki-67 positivity was $80 \%$. Negative expression in CK, Oct3/4, Syn, CgA, CD177, Melan-A, GFAP, NSE, ACTH, PRL, TSH, LH and GH. Due to the abnormal increase of Ki67 index of the tumor, which suggested that the tumor proliferated rapidly. In addition, the tumor was not completely resected. Therefore, we recommended that the patient be treated with Gamma-Knife radiosurgery. So, the does of 15 Gy in the center and 6 Gy in the edge to the area of residual tumor was performed. And she was advised to receive a second dose of gamma knife six months later.
One month later, PET-CT showed increased glucose metabolism in sellar region, suggesting that the residual tumor was still active. No abnormal increase of FDG metabolism was found in other parts. On October 24, 2018, the patient had abnormal speech and behaviour. The enhanced MRI scan showed that the tumor metastasized to the lateral ventricle and the fourth ventricle, and subsequently was diagnosed as pituitary adenocarcinoma (Figure 3 A, B). After informed consent, the patients were treated with temozolomide 5-28 (In the first cycle, the drug was taken continuously for 5 days. The second cycle of treatment was performed after 23 days) oral chemotherapy: $150 \mathrm{mg} / \mathrm{m}^{2} /$ day for the first time and $200 \mathrm{mg} /$ $\mathrm{m}^{2} /$ day for the second time.

Four months after the operation, the patient developed somnolence and the visual acuity of both eyes further decreased. Enhanced CT and MRI scan showed that the lesions in sellar region were further enlarged and invaded hypothalamus (Figure $3 \mathrm{C}, \mathrm{D}, \mathrm{E}, \mathrm{F}$ ). With the informed consent, she was treated with fractionated external beam radiation therapy (45 Gy in 25 fractions to the sellar region; total spinal cord, 36Gy). The volume of sellar region tumor decreased after radiotherapy (Figure $3 \mathrm{G}, \mathrm{H}$ ).

Unfortunately, seven months after the operation, the patient suffered from myelosuppression (decrease in all three lines of cells), further decrease of visual acuity (limited to light perception), bilateral blepharoptosis, and eventually died.
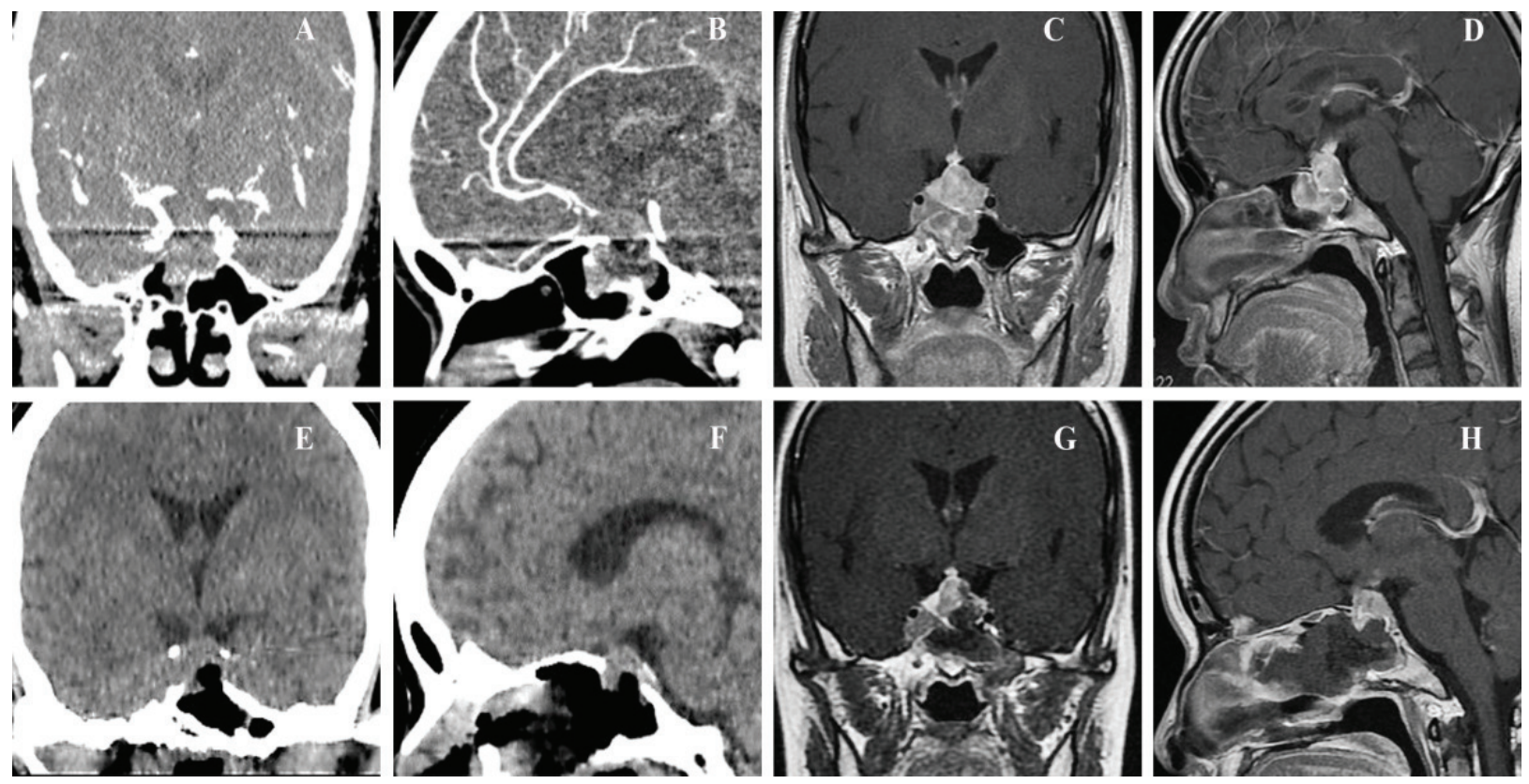

Figure 1: CT and MRI scan before and after operation. (A, B): Preoperative enhanced CT scan showed that the tumor broke through the sellar floor and protruded into the sphenoid sinus. (C, D) Preoperative enhanced MRI scan, which showed that the tumor invaded cavernous sinus, sphenoid sinus and grew to suprasellar cistern (Hardy 4a, Knosp 3). (E, F) Postoperative CT scan. $(G, H)$ Postoperative enhanced MRI scan, which indicated that the tumors in sphenoid sinus were resected, and some tumors in cavernous sinus and sella remained. 

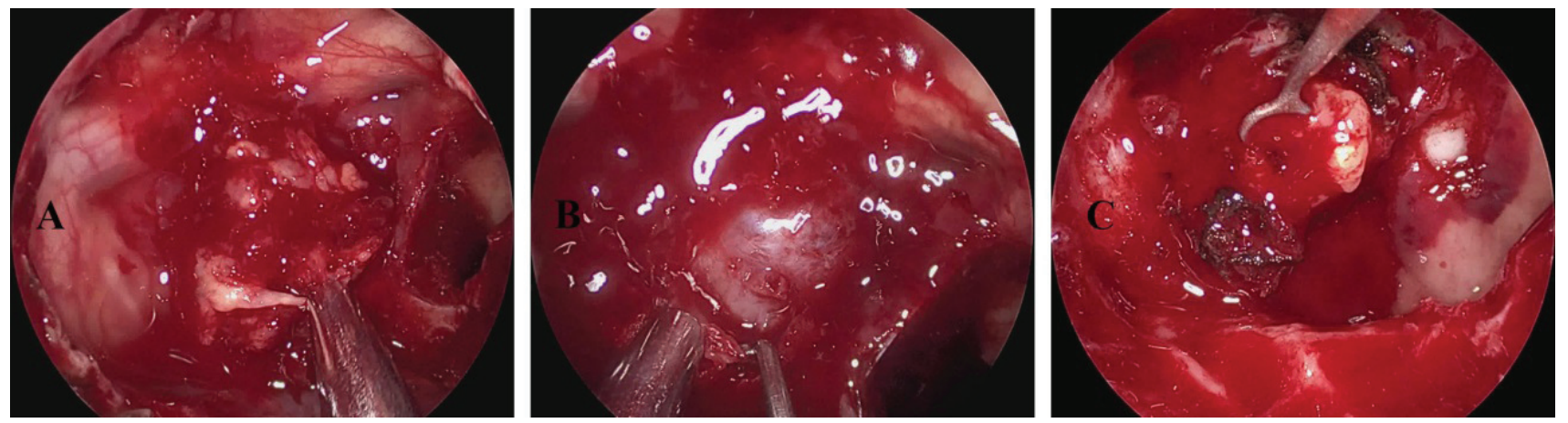

Figure 2: Intraoperative endoscopic images. (A) showed the tumor protruding into the sphenoid sinus, (B) was the dura mater of sellar floor, and there was a small tear in the dura mater, through which the tumor invaded the sphenoid sinus. (C) showed intrasellar tumor resection.
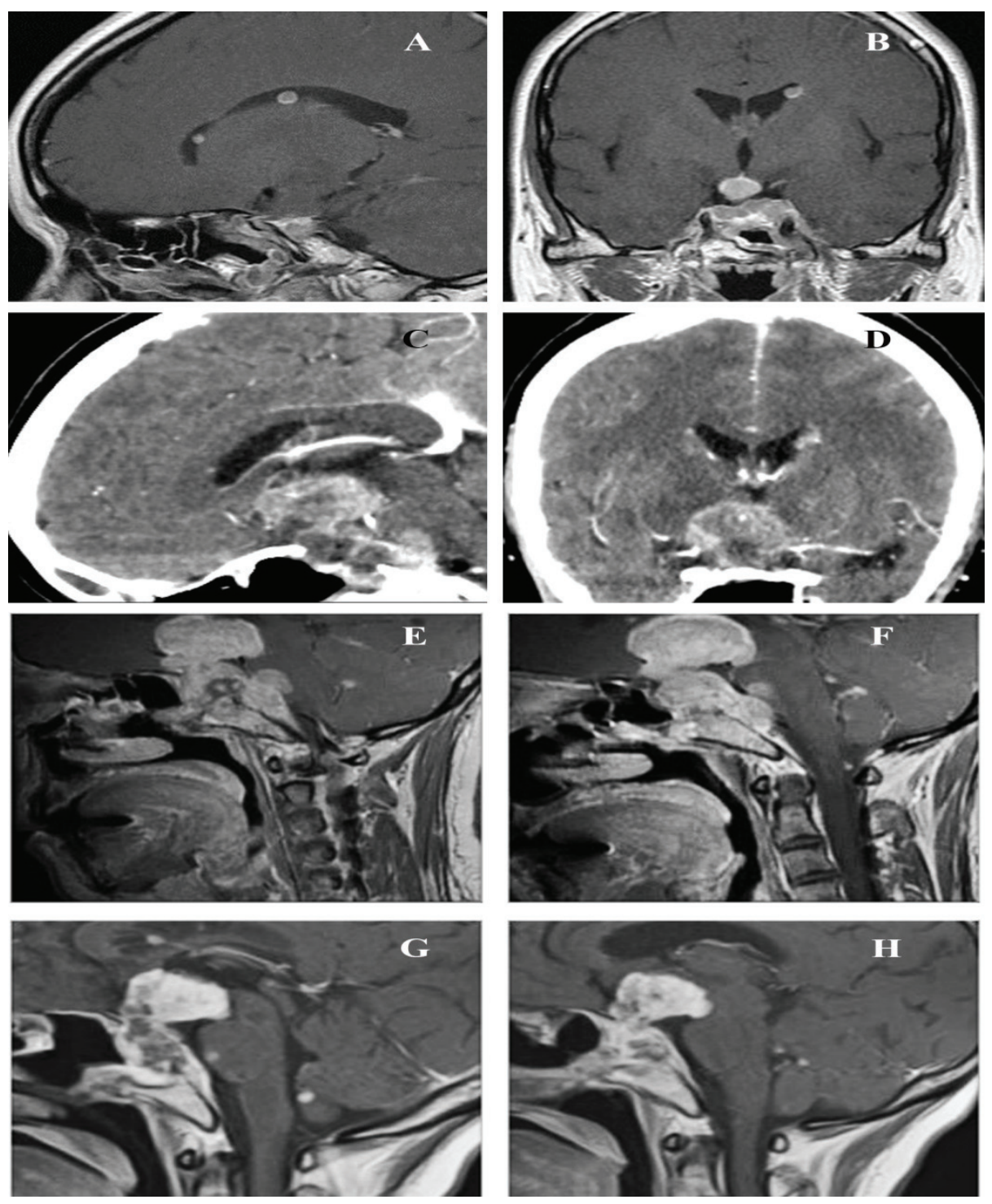

Figure 3: (A, B) two months after operation, enhanced pituitary MRI scan showed residual tumor in sellar region with intraventricular metastasis. After two-stage temozolomide treatment (4 months after operation), enhanced CT showed that the tumor was poorly controlled and continued to grow. $(C, D)$ Comparison of sagittal enhanced MR images of before (E, $F)$ and after $(G, H)$ whole craniospinal radiotherapy. It showed that the volume of lesions in sellar region decreased after radiotherapy. 


\section{Discussion}

\section{Epidemiology}

Pituitary adenocarcinoma accounts for $0.1 \%-0.2 \%$ of pituitary adenomas. ${ }^{3}$ The average age of onset is 44 years. $77 \%$ of pituitary adenocarcinoma has endocrine activity. ATCH (42\%) and PRL (33\%) are the main causes. About $66 \%$ of the patients died within 1 year after diagnosis. Up to now, there were only 38 cases of NFPC reported in the literature. This case was diagnosed as NFPC when metastasis was found 2 months after operation. Despite having received active comprehensive treatment, the patient still died 7 months after operation.

\section{Can pituitary carcinoma be diagnosed earlier?}

The differentiation between invasive pituitary tumor and pituitary carcinoma mainly depends on whether there is metastasis, which often leads to delayed treatment and disease progression. ${ }^{4}$ Increased mitosis and high nuclear atypia are of little value in the differential diagnosis of benign and malignant pituitary tumor. ${ }^{5}$ Studies have shown that in most cases of pituitary carcinoma, Ki-67 is higher than $10 \%$, and p53 is positive. ${ }^{4}$ So, it has been proposed that whether $\mathrm{Ki}-67$ can be used as the diagnostic criteria of pituitary carcinoma; and as an independent indicator of the choice of treatment time. However, there is still no consensus.

Somescholars putforward the concept of "premetastatic pituitary carcinoma"; Ki-67 $>30 \%$ is "pituitary carcinoma in situ". In these cases, they suggested radiotherapy and chemotherapy should be carried out as early as possible. ${ }^{6}$ For highly suspected cases of pituitary carcinoma, whole brain and whole craniospinal irradiation is recommended as soon as possible, even if there is no evidence of tumor metastasis along the cerebrospinal fluid. ${ }^{7}$ The total dose of conventional radiotherapy is 45-54 Gy, divided into 25-30 units. Stereotactic radiotherapy can be divided into five units with a total dose of $25 \mathrm{~Gy}$. However, some studies have found that radiotherapy can inhibit the growth of primary tumor and metastasis, improve the symptoms of patients, but does not effect overall prognosis.

This patient was treated with gamma knife after operation, but the tumor was still found to metastasize, and continue to progress after temozolomide chemotherapy, and then had received whole craniospinal irradiation. Although the tumor volume was controlled, the patient died 7 months after operation. This makes us wonder whether the choice of radiotherapy type may affect the prognosis, and whether whole brain and whole craniospinal irradiation should be the first choice.

\section{Chemotherapy}

Temozolomide has been used as a first-line chemotherapy drug in the treatment of refractory pituitary adenoma or pituitary adenocarcinoma. ${ }^{8}$ The low expression of MGMT indicates that the tumor has a good response to temozolomide. ${ }^{9}$ The low expression of MGMT in prolactin adenocarcinoma can reach $80 \%$, so prolactin adenocarcinoma has better response to temozolomide. ${ }^{10}$ The effective response rate of NFPC to temozolomide is about $37 \%$ lower than that of functional adenocarcinoma, the median survival time of NFPC is 8 months. ${ }^{2}$

The patient was diagnosed as NFPC after the occurrence of intraventricular metastasis, thereafter she was treated with temozolomide twice. However, her symptoms continued to worsen, and the tumor continued to grow. It had a poor response to temozolomide. So, genetic testing was carried to seek a breakthrough. However, no mutation of MGMT, IDH1/2 and $1 \mathrm{p} 19 \mathrm{q}$ was detected, which suggests that temozolomide may not be effective.

\section{When NFPC does not respond to temozolomide, how to choose treatment plan?}

The tumor was not sensitive to temozolomide, so we took tumor samples for gene testing. The results showed that PD-L1 was negative, MSS (microsatellite stabilization) and tumor mutational burden was $0.8 \mathrm{MutS}$ / MB, suggesting that the immunotherapy was ineffective. Only smarcb1 gene mutation was found in this sample. However, there is no drug for this gene mutation in the market

There are some cases reported in the literature for the treatment of pituitary adenocarcinoma with lapatinib, everolimus, ${ }^{11}$ lomustine $(\mathrm{CCNU})+5$-FU, ${ }^{12}$ bevacizumab, ${ }^{13}$ carboplatin, leucovorin and fluorouracil. ${ }^{14}$ However, because of the low incidence rate, it is difficult to conduct effective statistical analysis and prospective studies are difficult to carry out. Perhaps, the detection of tumor samples to guide the personalized treatment of drugs is a promising and reasonable procedure. At present, the consensus is to provide comprehensive and multidisciplinary treatment. ${ }^{2}$

\section{Conclusion}

NFPC is a rare disease with rapid progression and poor prognosis. There are no specific molecular biological diagnostic indicators, lack of effective diagnosis and treatment, clinical treatment is very difficult.

Therefore, we believe that for patients who are highly suspicious of having pituitary adenocarcinoma (p55+, $\mathrm{Ki}-67>30 \%$ ), it is necessary to quickly carry out surgery, obtain pathological specimens for detailed detection, at the same time, carry out systemic evaluation, which is not only helpful for early diagnosis, but also can provide the basis for the follow-up active treatment. Application of aggressive multi-modal therapy at presentation may be advantageous in some cases. 


\section{Non-functional Pituitary Carcinoma}

Conflict of Interest: None

Source of Support: None

\section{References}

1. Heaney A. Management of aggressive pituitary adenomas and pituitary carcinomas. J Neuro-Oncol. 2014;117:459-468. https://doi.org/10.1007/s11060014-1413-6

2. Kamiya-Matsuoka C, Cachia D, Waguespack SG, Crane CH, Mahajan A, Brown PD, Nam JY, McCutcheon IE, Penas-Prado M. Radiotherapy with concurrent temozolomide for the management of extraneural metastases in pituitary carcinoma. Pituitary 2016;19:415-421. https://doi.org/10.1007/ s11102-016-0721-6

3. Bengtsson D, Schrøder HD, Berinder K, Maiter D, Hoybye C, Ragnarsson O, Feldt-Rasmussen U, Krogh Rasmussen Å, van der Lely A, Petersson M, Johannsson G, Andersen M, Burman P. Tumoral MGMT content predicts survival in patients with aggressive pituitary tumors and pituitary carcinomas given treatment with temozolomide. Endocrine 2018;62:737-739. https://doi.org/10.1007/s12020018-1751-9

4. Jouanneau E, Wierinckx A, Ducray F, Favrel V, Borson-Chazot F, Honnorat J, Trouillas J, Raverot G. New targeted therapies in pituitary carcinoma resistant to temozolomide. Pituitary 2012;15:37-43. https://doi.org/10.1007/s11102-011-0341-0

5. Maira G, Doglietto F. Pituitary carcinoma: A devastating disease in need of an earlier diagnosis and of effective therapies. World Neurosurg. 2013;80:e143-e145. https://doi.org/10.1016/j. wneu.2011.06.025

6. Minniti G, Paolini S, Rea MLJ, Isidori A, Scaringi C, Russo I, Osti MF, Cavallo L, Esposito V. Stereotactic reirradiation with temozolomide in patients with recurrent aggressive pituitary tumors and pituitary carcinomas. J Neuro-Oncol. 2020;149:123-130. https://doi.org/10.1007/s11060-020-03579-5

7. Trouillas J, Jaffrain-Rea M, Vasiljevic A, Dekkers O, Popovic V, Wierinckx A, McCormack A, Petersenn S, Burman P, Raverot G, Villa C. Are aggressive pituitary tumors and carcinomas two sides of the same coin? Pathologists reply to clinician's questions. Reviews in Endocrine and Metabolic Disorders 2020;21:243251. https://doi.org/10.1007/s11154-020-09562-9

8. Buchfelder M, Schlaffer S. Surgical treatment of aggressive pituitary adenomas and pituitary carcinomas. Reviews in Endocrine and Metabolic Disorders 2020;21:253-261. https://doi.org/10.1007/ s11154-020-09563-8

9. AlMalki MH, Ahmad MM, Brema I, AlDahmani KM, Pervez N, Al-Dandan S, AlObaid A, Beshyah SA. Contemporary management of clinically non functionalNon functional pituitary adenomas: A clinical review. Clinical Medicine Insights: Endocrinology and Diabetes 2020;13:1839724052. https://doi.org/10.1177/1179551420932921

10. AbdelBaki MS, Waguespack SG, Salceda V, Jones J, Stapleton SL, Baskin DS, Okcu MF. Significant response of pituitary carcinoma to carboplatin, leucovorin and fluorouracil chemotherapy: A pediatric case report and review of the literature. J Neuro-Oncol. 2017;135:213-215. https://doi. org/10.1007/s11060-017-2554-1

11. Lenders $\mathrm{N}$, McCormack A. Malignant transformation in non functionalNon functional pituitary adenomas (pituitary carcinoma). Pituitary 2018;21:217-229. https://doi.org/10.1007/s11102-017-0857-Z

12. Lau Q, Scheithauer B, Kovacs K, Horvath E, Syro LV, Lloyd R. MGMT immunoexpression in aggressive pituitary adenoma and carcinoma. Pituitary 2010;13:367-379. https://doi.org/10.1007/ s11102-010-0249-0

13. Hansen TM, Batra S, Lim M, Gallia GL, Burger PC, Salvatori R, Wand G, Quinones-Hinojosa A, Kleinberg L, Redmond KJ: Invasive adenoma and pituitary carcinoma: A SEER database analysis. Neurosurg Rev. 2014;37:279-286. https://doi. org/10.1007/s10143-014-0525-y

14. Touma W, Hoostal S, Peterson RA, Wiernik A, SantaCruz KS, Lou E: Successful treatment of pituitary carcinoma with concurrent radiation, temozolomide, and bevacizumab after resection. J Clin Neurosci. 2017;41:75-77. https://doi. org/10.1016/j.jocn.2017.02.052 